\title{
Bochdalek diaphragmatic hernia masquerading as tension hydropneumothorax in an adult
}

\author{
Sanjay K. Somani, MD, DM, ${ }^{\mathrm{a}}$ Puneet Gupta, MS, DNB, FNB, ${ }^{\mathrm{b}}$ Shekhar Tandon, MS, MCh, ${ }^{\mathrm{c}}$ \\ Devendra Sonkar, MD, ${ }^{\mathrm{d}}$ Shirish Bhatnagar, MD, DNB,${ }^{\mathrm{a}}$ and Manish Saxena, MD, ${ }^{\mathrm{d}}$ Lucknow, India
}

\section{CLINICAL SUMMARY}

A 25-year-old man presented with upper abdominal pain and respiratory distress lasting for 4 days. On initial evaluation, he was having mild tenderness in the epigastrium and

From the Department of Gastroenterology, ${ }^{\mathrm{a}}$ Minimal Access Surgery, ${ }^{\mathrm{b}}$ Cardiothoracic Surgery, ${ }^{\mathrm{c}}$ and Radiology, ${ }^{\mathrm{d}}$ Sahara Hospital, Lucknow, India.

Disclosures: Authors have nothing to disclose with regard to commercial support.

Received for publication Nov 19, 2009; accepted for publication Nov 26, 2009; available ahead of print Feb 22, 2010.

Address for reprints: Sanjay K. Somani, MD, DM, Department of Gastroenterology, Sahara Hospital, Viraj Khand, Lucknow-226010, UP, India (E-mail: sanjayksomani@rediffmail.com)

J Thorac Cardiovasc Surg 2011;141:300-1 $0022-5223 / \$ 36.00$

Copyright $@ 2011$ by The American Association for Thoracic Surgery doi:10.1016/j.jtcvs.2009.11.062 reduced air entry on the left side of the chest. A succussion splash was heard on the left side of chest. A chest x-ray showed tension hydropneumothorax on the left side (Figure 1). In view of respiratory distress, an intercostal drain was inserted on the left side of the chest. The chest tube did not drain pleural fluid. The next day, a 64-slice computed tomography scan of the chest was done that showed a Bochdalek hernia with the stomach, colon, and left lobe of the liver in the thorax. The patient underwent operation, and at laparotomy the Bochdalek hernia was seen on the left side of the diaphragm posteriorly. The stomach, splenic flexure of colon, and left lobe of the liver were seen passing through the hernia into the thorax. The stomach had ischemic changes that reverted back to normal on
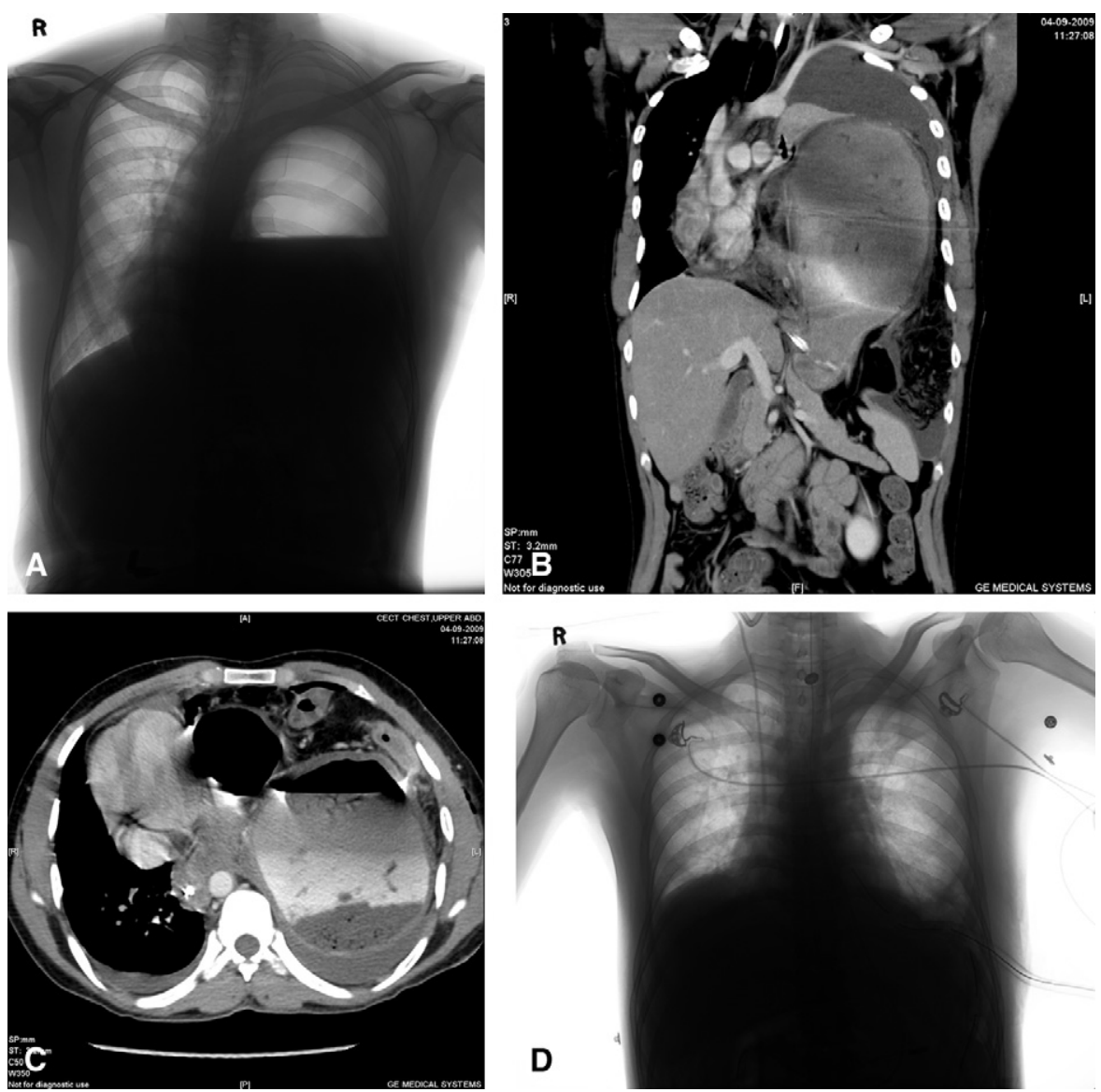

FIGURE 1. A, Chest X-ray showing the picture mimicking tension hydropneumothorax. B, C, 64-slice computed tomography scan of the chest and upper abdomen showing the herniation of the stomach and left lobe of the liver. D, Chest x-ray after surgery showing normal position of stomach and expanded left lung. 
reperfusion and application of hot packs. The stomach, colon, and liver were reduced, and the hernia was repaired. The patient's condition improved clinically, and the chest $\mathrm{x}$-ray showed a well-expanded left lung. The patient was discharged on the seventh day.

Congenital diaphragmatic hernias result from failure of fusion of the multiple developmental components of the diaphragm. Bochdalek hernias occur posterolaterally at the lumbocostal junctions of the diaphragm. Only a few Bochdalek hernias are first discovered in adulthood. ${ }^{1}$ Bochdalek hernias occur on the left side in approximately $80 \%$ of cases. ${ }^{2}$ In older children and adults, a Bochdalek hernia may manifest as an asymptomatic chest mass. The differential diagnosis includes mediastinal or pulmonary cyst or tumor, pleural effusion, or empyema. Symptoms, when present, are due to herniation of the stomach, omentum, colon, or spleen.

A Bochdalek diaphragmatic hernia that was initially misdiagnosed as pneumonia with massive pleural effusion has been described. ${ }^{3}$ A report of a 76-year-old man with a right-sided Bochdalek hernia who was admitted acutely with dyspnea has been described ${ }^{4}$ computed tomography of the abdomen revealed marked elevation of the right hemidiaphragm caused by herniation of the colon. The prevalence of the incidentally diagnosed asymptomatic posterior diaphragmatic hernias in the age groups 50 to 59 years, 60 to 69 years, and 70 to 79 years was $10.5 \%$,
$13.7 \%$, and $20.3 \%$, respectively, in a prospective study of chest computed tomography. ${ }^{5}$

\section{CONCLUSIONS}

Laparoscopic and thoracoscopic repair of the Bochdalek hernia have been described. ${ }^{6,7}$ There were no statistically significant differences in complications, additional related operative procedures, use of prosthetic patch, recurrence, length of stay, or postoperative mortality between the thoracoscopic repair and open repair groups. ${ }^{7}$

\section{References}

1. Guttman FM, Laberge J-M. Congenital diaphragmatic hernia. In: Nyhus LM, Condon RE, eds. Hernia. Philadelphia: Lippincott; 1989:694.

2. Langer JC. Congenital diaphragmatic hernia. Chest Surg Clin North Am. 1998;8 295

3. Chiu CC, Yeh HF, Chiu TF. Bochdalek diaphragmatic hernia masquerading as pneumonia-a rare cause of non-traumatic hemothorax. Am J Emerg Med. 2009;27:252. e1-2.

4. Kavanagh DO, Ryan RS, Waldron R. Acute dyspnoea due to an incarcerated rightsided Bochdalek's hernia. Acta Chir Belg. 2008;108:604-6.

5. Kinoshita F, Ishiyama M, Honda S, Matsuzako M, Oikado K, Kinoshita T, et al Late-presenting posterior transdiaphragmatic (Bochdalek) hernia in adults: prevalence and MDCT characteristics. $J$ Thorac Imaging. 2009;24:17-22.

6. Palanivelu C, Rangarajan M, Rajapandian S, Amar V, Parthasarathi R. Laparoscopic repair of adult diaphragmatic hernias and eventration with primary sutured closure and prosthetic reinforcement: a retrospective study. Surg Endosc. 2009;23: 978-85. Epub 2009 Mar 14

7. Cho SD, Krishnaswami S, Mckee JC, Zallen G, Silen ML, Bliss DW. Analysis of 29 consecutive thoracoscopic repairs of congenital diaphragmatic hernia in neonates compared to historical controls. J Pediatr Surg. 2009;44:80-6.

\title{
"Freezing" the left ventricular outflow tract for homograft reconstruction in aortic root endocarditis
}

\author{
Daniel Pereda, MD, and Soon J. Park, MD, Rochester, Minn
}

Root replacement with cryopreserved homografts is frequently used to treat active endocarditis. To alleviate concerns with tissue fragility, it would be desirable to stabilize the left ventricular outflow tract (LVOT) and aortic annulus. We report the case of a patient with active endocarditis who underwent placement of an aortic root homograft

\footnotetext{
From the Division of Cardiovascular Surgery, Mayo Clinic, Rochester, Minn. Disclosures: Authors have nothing to disclose with regard to commercial support. Received for publication April 29, 2010; accepted for publication May 5, 2010; available ahead of print July 5, 2010.

Address for reprints: Soon J. Park, MD, Mayo Clinic, Division of Cardiovascular Surgery, 2001 st St SW, Rochester, MN 55905 (E-mail: park.soon@mayo.edu). J Thorac Cardiovasc Surg 2011;141:301-3 $0022-5223 / \$ 36.00$

Copyright (c) 2011 by The American Association for Thoracic Surgery doi:10.1016/j.jtcvs.2010.05.005
}

protected by a novel technique of "freezing" the LVOT with a circumferential continuous suture and a sizer.

\section{CLINICAL SUMMARY}

A 35-year-old man with a history of intravenous drug abuse and aortic valve replacement with a mechanical prosthesis 7 years previously for a bicuspid valve with severe regurgitation was transferred to our institution with the diagnosis of complicated prosthetic valve endocarditis. The diagnosis was made after the incidental finding of multiple embolic infarcts in brain, liver, kidney, and spleen after a motor vehicle accident. Serial blood cultures grew methicillin-sensitive Staphylococcus aureus, and transesophageal echocardiography revealed extensive perivalvular involvement with periannular abscess and cavitation on the mitroaortic curtain. 